\title{
Overcoming calorie calculation challenges for fried foods within $\mathrm{MenuCal}^{\circledR}$
}

\author{
F. E. Douglas ${ }^{1}$, S. J. Williams ${ }^{1}$, E. M. Keaveney ${ }^{1}$, S. M. Ní Bhriain ${ }^{1,2}$ and M. A. T. Flynn ${ }^{1,2}$ \\ ${ }^{1}$ Public Health Nutrition, Food Safety Authority of Ireland, Dublin 1, Republic of Ireland and ${ }^{2}$ Northern Ireland Centre \\ for Food and Health, University of Ulster, Coleraine BT52 1SA, UK
}

The estimation of oil/fat absorption by foods during deep or shallow frying is a major challenge when calculating the calorie content of some recipes. The aim of this study was to develop and validate a method within $\mathrm{MenuCal}^{\mathrm{O}(1)}$ for calculating calories, within a tolerance of $\pm 30 \%$ accuracy, for recipes necessitating estimation of oil/fat absorption during frying.

The amount of oil/fat absorbed during shallow and deep fat frying has been directly estimated for a variety of foods grouped into 39 categories $^{(2)}$. This data was used to apply fat absorption factors to all foods in $\mathrm{MenuCal}^{\mathrm{C}}$. A 'fat absorption' process was integrated into the $\mathrm{MenuCal}^{\circ}$ software which prompts users to choose a method of frying, the type of fat/oil being used and, if necessary, the addition of a batter or crumb. For validation, foods that have a calorie value for both raw and fried versions were identified from $\mathrm{CoF}$ $\operatorname{IDS}^{(3)}$ ( $n 93$ pairs) and grouped into four food types. Calorie values for the fried versions of these foods were calculated using the $\mathrm{MenuCal}^{\odot}$ process. This is based on CoF IDS calorie values for $100 \mathrm{~g}$ of the raw foods plus the calorie estimation for oil/fat absorbed during frying using the fat absorption factors. The resulting calorie values were compared with calorie values for the fried versions of these food in CoF IDS (amounts equivalent to $100 \mathrm{~g}$ raw weight adjusted for weight yield during cooking) ${ }^{(2,4)}$. Pearson's correlation co-efficient was used to assess the relationship between the proportional variation in calorie values obtained using the two methods ( $\%$ difference in values estimated by MenuCal ${ }^{\mathcal{O}}$ compared with $\mathrm{CoF}$ IDS values - see table) and the CoF IDS calorie values of the fried foods.

\begin{tabular}{|c|c|c|c|}
\hline Fried Food Groups $(n)$ & kcal using $\mathrm{MenuCal}^{\mathrm{O}} \S$ median (range) & kcal using CoF IDS¥ median (range) & $\%$ difference* median (range) \\
\hline 1. Total $(93)$ & $186(22-358)$ & $188(34-426)$ & $-23(-148-82)$ \\
\hline 2. Bread, Potatoes and Pasta (5) & $125(115-298)$ & $153(121-357)$ & $-16(-1--18)$ \\
\hline 3. Vegetables $(21)$ & $27(22-195)$ & $61(34-222)$ & $-45(-80--12)$ \\
\hline 4. Meat, Fish and Poultry (39) & $168(95-291)$ & $168(88-320)$ & $4(-53-37)$ \\
\hline 5. Processed Meat and Fish Products (28) & $241(180-358)$ & $214(173-426)$ & $3(-36-39)$ \\
\hline
\end{tabular}

$\S$ A calorie calculator for use by food businesses to enable calorie menu labeling.

$¥$ The UK Composition of Foods Integrated Dataset (CoF IDS).

* The $\%$ difference in kcal values estimated by $\mathrm{MenuCal}^{\circ}$ compared with $\mathrm{CoF}$ IDS kcal values.

As shown in the table, median calorie values for all of the food groups, estimated using $\mathrm{MenuCal}^{\circ}$, were comparable with $\mathrm{CoF}$ IDS values and, with the exception of the vegetable group, all fell within the $\pm 30 \%$ variation tolerance limit. Overall a weak negative correlation was observed between the proportional variation in calorie values and the calorie content of the fried foods $(\mathrm{r}=-0.28)$. However, this correlation was stronger for foods with a lower calorie content $(r=-0.43$ for foods below the median CoF IDS calorie value). This indicates that the variation between calorie values estimated using $\mathrm{MenuCal}^{\mathbb{O}}$ compared with $\mathrm{CoF}$ IDS, is greatest for fried foods with a lower calorie content.

The method developed to calculate the calorie content of fried food recipes in $\mathrm{MenuCal}^{\odot}$ was comparable with $\mathrm{CoF}$ IDS values, within a $\pm 30 \%$ tolerance limit, for most foods tested. As underestimation was greatest for the foods with the lowest calorie content, the impact on variation in amount of calories calculated per serving is low.

1. Flynn MAT, Douglas FE, Williams SJ et al. (2014) Proc Nutr Soc (Submitted).

2. Bognár A (2002). Tables on weight yield of food and retention factors of food constituents for the calculation of nutrient composition of cooked foods (dishes). Bundesforschungsanstalt für Ernährung.

3. Food Standards Agency (2002) McCance and Widdowson's The Composition of Foods integrated dataset (CoF IDS). http://www.food.gov.uk/ science/dietarysurveys/dietsurveys/ (accessed January 2014).

4. Bergström L (1994) Nutrient losses and gains in the preparation of foods. Rapport-Livsmedelsverket. 